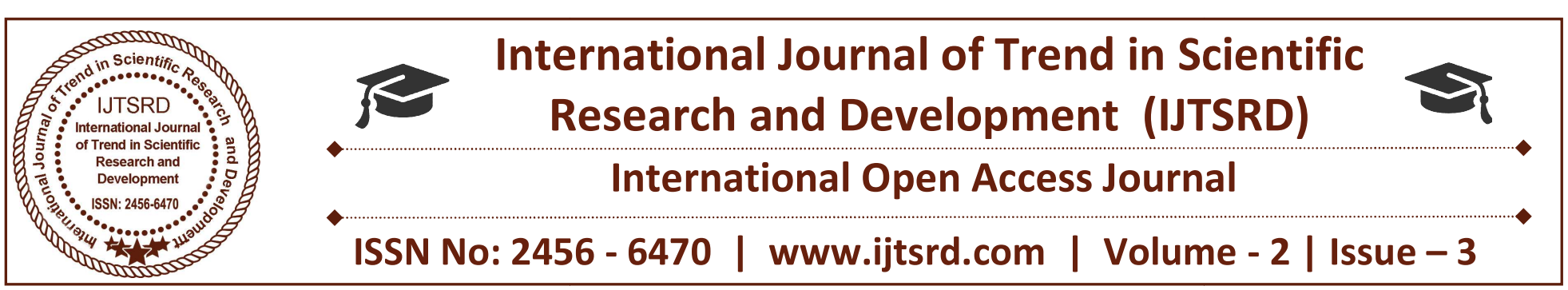

\title{
Support Network of Visually Challenged Women in Tiruchirappalli City, Tamil Nadu
}

\author{
Rajathurai Nishanthi \\ Ph.D Research Scholar, Department of Sociology, \\ Bharathidasan University, \\ Tiruchirappalli, Tamil Nadu, India
}

\author{
Dr. S. Sampathkumar \\ Professor and Head, Department of Sociology \& \\ Population Studies, Bharathiar University, \\ Coimbatore, Tamil Nadu, India
}

\section{ABSTRACT}

This study aimed to identify the support network especially family support system of visually challenged women. Women with visually challenged is one of the greatest a significant social issue globally. The family support as an informal network that provides individuals, with expressions of emotional concern or empathy. The descriptive nature of this study was undertaken - with the objectives of the family support network of visually challenged women in Tiruchirappalli city, Tamil Nadu. The sample of 42 visually impairment women aged 24 and above 44 years of age were selected through purposive sampling technique. An interview schedule and observation was used for collection of data. $83.3 \%$ of visually challenged women have received good emotional support from their family. Almost maximum number of women with visual impairment got good personal support like the household task, cleaning, handling money, support during pregnancy period, care of children etc. The study has shown that having good family support is a strong protective factor against negative things such as depression, isolation, poverty and helps to increase well-being.

Keywords: visually challenged, family support, socioeconomic condition

\section{INTRODUCTION}

Visually challenged people are in many parts of the world. They face a lot of problems in their life and they have to depend on others for satisfying their needs. The visually challenged, those who are either blind or have low vision, have a reduced ability to perform many tasks which are considered trivial to the sighted. They are often alienated from mainstream society because of their inability to interact in what many would consider a "normal way." Visually challenged leads to social isolation and unequal opportunities. Women with visually challenged is one of the greatest a significant social issue globally. According to World Health Organization,(2016), estimated that there are more than 600 million people with disability in the world, this represents $20 \%$ of the world's population. Among them, 285 million people are visually impaired in the world (exist among certain age, sex, socio-demographic, racial, and geographic subgroups.) from all causes; of these, 39 million blind across the globe who are blind 246 million having low vision. As per the Census 2011 show the Indian scenario of visual impairment is over 45 million people are still from India (15 million blind), in which 80 percent of them live in remote and isolated villages.

The family support as an informal network that provides individuals, with expressions of emotional concern or empathy. Family support means the support of family during a crisis has long been seen to have a positive emotional effect on people. Family support of visually challenged women is considered the most significant factor to lead their day to day activities and maintain the emotional balance. Many studies also show that family may have a positive impact on their life and it is reducing emotional conflict. Family is the most precious social institution in India and the most vital non-formal social security 
for the visually challenged women. In recent years Indian society is experiencing a gradual but definite change in the traditional and conventional family system. These changes have notable implications on the status and support of visually challenged women. Thus a study on family support of visually challenged is necessary for analyzing the existing structure of family support and the nature and extent of family relations.

\section{SIGNIFICANCE OF THE STUDY}

Around the world, women make up just over $51 \%$ of the population. Women with visually challenged do not form a homogeneous group. They are multiplying disadvantaged by their status as women, and majority numbers of Indian visually impaired women are living in poverty. Women with visually challenged are the most marginalized in India. In addition, they are exposed to social stigma and stereotyping within their community, which leads them to feel devalued, isolated, and ashamed. Visual impairment brings profound economic disadvantage to individuals, their families and societies.

Several recent studies have quantified these impacts. Many of the causes of avoidable blindness in lowincome countries are directly related to poverty, including hunger, malnutrition and limited access to health, education, water and sanitation services. These problems are most acute in the least economically developed regions, Impairment is very specific and individual to that person alone touches every aspect of that individual's life experience, manifesting itself in physical, emotional, psychological, environmental, educational, social, spiritual and financial dimensions. There are many types, causes and images of disability and they face many barriers, including separation, segregation, stereotyping, labeling, prejudice and stigma. Misunderstood or inappropriate terminology, barriers to communication and information, and inaccessible environments also make disabled people's lives unnecessarily difficult. In this study family support system of visually challenged women are basically three levels that are emotional support, financial support, and personal support. Women with visual impairment, depends to a great extent on the support the person gets from her family members.

\section{REVIEW OF LITERATURE}

Fauzia Khurshid et.al (2011) examined a study on the perception of visually impaired about familial, academic and caregivers support. The study targeted to explore the difference in the perception of support of visually impaired youth living in the residential institute. A questionnaire consisting of 28 items developed through standardizes procedure and used for data collection. The sample of the study was involved of 100 students. Among them 58 were boys and 42 were girls, ages ranged from 15 to 22 years, they belong to different socioeconomic status. The result of the study revealed that the performance and attitude of caregivers are not satisfactory; moreover, residential facilities are also not enough.

Lola Marson (2003) conducted a study on the impact of the rehabilitation programme offered by the agencies of the Caribbean Council for the Blind on the status of blind and visually impaired women in the region. The sample consisted of 100 blind and visually impaired women from four Caribbean islands, namely, Barbados, Jamaica, St. Lucia and Trinidad. The method of data collection used was questionnaires, which, consisted of thirty-nine questions incorporating five major variables. The findings revealed that the impact of the programme was positive in the areas of independent travel, decision-making in the home, the performance of household duties and on self- confidence.

Clare Thetford et.al (2011) conducted study on longterm access to support for people with sight loss. Data from biographical interviews with 36 participants with sight loss is presented, with the particular focus on three illustrative case studies. The study reveals that many participants experienced problems gaining information about, and access to, services in the short and longer term. There is a need for the systematic referral of clinical services to social and voluntary services and for the regular follow-up to identify and respond to people's changing needs.

Suzanne Hodge et.al (2013) conducted on exploring the role of an emotional support and counseling service for people with visual impairments. There was growing evidence of the need for services to address the emotional support needs of people with visual impairments. Findings from a mixed methods evaluation of an emotional support and counseling service delivered within an integrated low vision service, focusing primarily on the qualitative findings. Data collected using a standardized measure of psychological well-being show an improvement in the psychological well-being of clients of the service between baseline and follow-up assessment. Qualitative findings from interviews with service users and service providers help to illustrate and explain the experiences underlying the quantitative 
findings. The services are shown to be helpful to service users in two particular ways: helping them to normalize their experiences by talking to an impartial listener and helping them to accept and adapt to the physical, emotional and social changes in their lives resulting from their visual impairment.

The paper arises from research funded by the Housing Corporation and Thomas Pocklington Trust, which investigated the housing and support needs and priorities of visually impaired people of working age, a population that has received little public policy attention. It reports on an in-depth study of the circumstances and aspirations of 121 people living in London, which revealed a need for increased opportunities to access information, personal support, employment, and housing. The study also discovered strategies that this sample believed would address such need, including better professional collaboration and training, consultation and partnership, and facilitative housing provision (John Percival and Julienne Hanson, 2007).

\section{METHODOLOGY}

The descriptive nature of this study was undertaken with the objectives of family support system of visually challenged women in Tiruchirappalli,-Tamil Nadu. The sample of 42 visually impairment women aged 24 and above 44 year of age were selected through purposive sampling technique. An interview schedule and observation was used for collection of data.

\section{RESULT AND DISCUSSION}

Table: 1. Demographic Profile of Respondents $(\mathrm{N}=42)$

\begin{tabular}{|lcc|} 
Variables & $\begin{array}{c}\text { No. of } \\
\text { Respondents }\end{array}$ & Percentage \\
\hline Age & 4 & $9.5 \%$ \\
\hline $24-29$ & 17 & $40.5 \%$ \\
\hline $30-34$ & 20 & $47.6 \%$ \\
\hline $35-39$ & 1 & $2.4 \%$ \\
\hline $40-44$ & & \\
\hline Occupation & 7 & $16.7 \%$ \\
\hline Agarbatti business & 3 & $7.1 \%$ \\
\hline Beggaring & 2 & $4.8 \%$ \\
\hline Singing & 30 & $71.4 \%$ \\
\hline ouse wife & & \\
\hline Type of family & 28 & $66.7 \%$ \\
\hline Nuclear family & 14 & $33.3 \%$ \\
\hline Joint family &
\end{tabular}

Table. 3 Level of Family Support of Visually Challenged Women $(n=42)$

Family support frequency Percent

A. Emotional support

\begin{tabular}{|lcc|}
\hline Low level & 07 & 16.7 \\
\hline High level & 35 & 83.3 \\
\hline B. Financial support & & \\
\hline$\quad$ Low level & 33 & 78.6 \\
\hline High level & 09 & 21.4 \\
\hline C. Personal Support & & \\
\hline$\quad$ Low level & 09 & 21.4 \\
\hline High level & 33 & 78.6 \\
\hline
\end{tabular}

Source: Primary Data

Table: 2. Demographic Profile of Respondents $(\mathrm{N}=42)$

\begin{tabular}{|lll|}
\hline Variables & $\begin{array}{l}\text { No. } \\
\text { Respondents }\end{array}$ \\
\hline Marital status & Percentage \\
\hline Married & 40 & $95.2 \%$ \\
\hline Widow & 2 & $4.8 \%$ \\
\hline $\begin{array}{l}\text { Disability condition of } \\
\text { husband }\end{array}$ & \\
\hline Blind & 29 & $69 \%$ \\
\hline Partial vision & 7 & $16.7 \%$ \\
\hline $\begin{array}{l}\text { Normal vision but other } \\
\text { disability (Deaf) }\end{array}$ & 6 & $14.3 \%$ \\
\hline $\begin{array}{l}\text { monthly income of } \\
\text { your family }\end{array}$ & & \\
\hline $\begin{array}{l}\text { Rs.2000-Rs.3500 } \\
\text { Rs.4000-Rs.5500 }\end{array}$ & 9 & $21.4 \%$ \\
\hline
\end{tabular}

Source: Primary Data

The data reveals that majority in the age group of 3539 years and more than $70 \%$ of them were house wives. They recorded a monthly family income ranging from Rs. 2000 to Rs. 5,500, moreover they come under the lower income group because they do not have equal opportunity to participate in ever work and excluded from main stream of the society. Majority of them reported disability condition of spouses was blind $(69 \%)$ and $14.3 \%$ of spouse of visually challenged women has other type of disability like deafness.

Source: Primary Data 
The data reveals that family support is included three sub items such as emotional support, financial support, personal support $83.3 \%$ of respondents have received good emotional support from their family. Maximum number of women got positive emotional support from their parents, siblings, spouse, children and any other close relative. The family has provided good support in time of their ill health and cared them well. Nevertheless, compare to three support system (Emotional support, financial support, Personal Support) women with visual impairment have less financial support than other two support system reason for that family of women with visual impairment also facing the condition of poverty, unemployment, underemployment etc. Hence family members could not support them financially.

\section{CONCLUSION}

There are many problems for visually challenged women in society, they face many type of hurdles in performing every day routine works and encounter embarrassment many times while performing the tasks, to highlight very specifically, when they are unsuccessful in performing or completing them. Families are society's most important building block and strong families equate to strong communities because they embody caring for others, connectedness with people, and providing hope, support and comfort. The study has shown that having good family support a strong protective factor against negative things such as depression, isolation, poverty and helps to increase well-being. Women with visually challenged have good family support even though financial help of family was less than other kind of family support.

\section{Reference}

1) Abou-Gareeb et.al(2001)Gender and blindness: a meta-analysis of population-based prevalence surveys. Ophthalmic Epidemiology. 2001 vol 8(1) pp. 39-56.

2) Abu-Lughod, L. (1998). Feminist longings and postcolonial conditions. In L. Abu-Lughod (ed.), remaking women: Feminism and modernity in the middle east. (pp. 3-31). Princeton, NJ: Princeton University Press.

3) Al-Merjan et.al (2005) Registered blindness and low vision in Kuwait. Ophthalmic Epidemiol. 12(4):251-7.
4) Aroral and Shetty (2014) Common Problems Faced By Visually Impaired People International Journal of Science and Research (IJSR) Vol (3)10.

5) Anna Rius, et.al (2012) Social inequalities in blindness and visual impairment: A review of social determinants Indian $\mathrm{J}$ Ophthalmol. Vol 60(5) pp. 368-375.

6) Blumberg, R. L. (1978). Stratification: Socioeconomic and sexual inequality. Dubuque, 1A: William C. Brown.

7) Blumberg, R. L. (1979). A paradigm for predicting the position of women: Policy implications and problems. In J.

8) Dandona et.al (2001) Blindness in the Indian state of Andhra Pradesh. Invest Ophthalmol Vis Sci. 42(5):908-16.

9) Geneau et.al (2005)The social and family dynamics behind the uptake of cataract surgery: Findings from Kilimanjaro Region, Tanzania. Br J Ophthalmol. Vol ;89:1399-1402.

10) Groenveld, M. (1993) Effects of visual disability on behaviour and the family. In Fielder, A.R., Best A.B., Bax, M.C. (eds) The Management of visual impairment in childhood. London: Cambridge University Press. 